\title{
USE OF VIRTUAL CLASSROOM AS A TOOL FOR E-LEARNING IN THE MASTER
}

\author{
Josep Esteve-Romero ${ }^{1}$, Juan Peris-Vicente ${ }^{2}$, Jaume Albiol-Chiva ${ }^{1}$, Samuel \\ Carda-Broch ${ }^{1}$, Estel.la Esteve-Amorós ${ }^{3}$, María José Ruiz Ángel ${ }^{2}$, Mar Esteve- \\ Amorós $^{2}$, Dolores Yusá-Marco ${ }^{3}$, María Teresa Doménech-Carbó ${ }^{3}$, Luis Álvarez- \\ Rodríguez ${ }^{4}$, Diego Kassuha ${ }^{5}$ \\ ${ }^{1}$ Universitat Jaume I (SPAIN) \\ ${ }^{2}$ Universitat de València (SPAIN) \\ ${ }^{3}$ Universitat Politècnica de València (SPAIN) \\ ${ }^{4}$ IES Vicente Castell (SPAIN) \\ ${ }^{5}$ Universidad Católica de Cuyo (ARGENTINA)
}

\begin{abstract}
The Virtual Classroom is an essential tool for e-learning. This teaching strategy depends on the accessibility of professors and students to the web, and how they deal with internet resources. The Master of Analytical Techniques of the Clinical Laboratory (TALC), taught at the University Jaume I, has undergone important changes in the last two years: it began offering traditional face-to-face classes, and it has recently turned into an almost distance-taught Master. The adaptation of the professors depended on their origin: half the Hospital workers do not use internet tools, while University lecturers prefer them. Otherwise, the students prefer to get access to the documents (articles and didactic units) by on-line tools. Only a $10 \%$ of the students asked to receive the didactic material in paper, because they did not have access to internet. The main conclusion were that the institutions using e-learning must implement several support actions for distance students, like to offer courses about the management of web tools and websites, and provide free and unlimited access to internet. Besides, we found that the library is highly important as information source, in both the University and the professional career.
\end{abstract}

Keywords: e-learning; Master; Student support system; Virtual Classroom; University.

\section{INTRODUCTION}

Nowadays, the education community and the society are claiming the implementation of didactic methodologies, which replaces those currently used. Therefore, the breakthroughs in the communication technology would be exploited to propose new teaching strategies, and improve the quality of the education system, but maintaining the advantages of the traditional methods. This is especially demanded to the University, which is supposed to be permanently at the forefront of innovation and education.

Traditional approaches are limited by: the number of students that can attend the face-to-face lectures, the duration of the academic course and that of each lecture, the space and equipment available for each class, the cost of the development of each methodology, and the lack of adaptability and accessibility, as the students do not have access to learning every time and everywhere. This problematic is enhanced in the Master, as many students must work or take care of relatives, and then have greater constraints to attend the lecture and perform the homework tasks.

For many years now, several educational institutions have developed and implemented alternative didactic strategies based in distance learning, such as correspondence courses. Nevertheless, these methodologies have not reached the same degree of efficiency as the face-to-face courses. The emergence and popularization of internet and the refinement and adaptability of a new generation of software structures, specifically designed for e-learning, have allowed the development of an innovative and way-out didactic methodology implemented through a computer: the Virtual Classroom (VC). This tool can be used to support the face-to-face classes and to teach the content fully by elearning.

The experiences in the VC are related to an asynchronous and synchronous interaction, the characteristics of the lecturers and the students, and the convenience, adaptability and versatility of the VC. The entire learning process is carried out with a complete flexibility (at any time) and 
accessibility (anywhere). This feature cannot be reached using the traditional didactic approaches. The student becomes an active participant of the teaching-learning process, but individually acquires the content of the subject, irrespective of the learning pace of the other students. The VC is a "nonphysical work area" to support and strengthen the learning of the students, including the acquisition and transmission of the knowledge among students themselves and the self-evaluation. This internet tool allows the distribution and sharing of information and documents related to the subject, ideas and experiences, as well as the evaluation of the lecturers by the students.

The VC of the University Jaume I (UJI) is a teaching-learning environment located in a communication system based on the web. It offers an improved access to advanced educational experiences, because it allows to students and lecturers to share documents, books, articles, websites and other didactic material in digital format, as well as to contact with remote learning communities. It permits several ways of communication between lecturers and students, as well as among students themselves: on-line discussions, debates, group or individual schedule, tutoring, presentations of the students, e-mail, students proposal about the organization and the content of the subject, adequacy of the didactic material, etc; all moderated and leaded by the lecturer. For these reasons, this is an interesting tool to involve the students in the elaboration and development of the subject, to stimulate their participation in class and facilitate the communication with the lecturer. Besides, a software specifically designed to support cooperative learning in all subject has been incorporated. Therefore, the use of the VC makes easier the adaptation of the subject and its course syllabus to the process of European convergence and to the current requirements and needs of the society.

\section{OBJECTIVES}

The main objective of this paper is to comment the experience in the use of the VC in several subjects in the Master of Analytical Techniques of the Clinical Laboratory, as supplement of the face-to-face classes. All the study was performed under the supervision of the lecturers, which keep the student in a secure and risk-free environment.

The communication and the participation of the students in the discussions, debates and opencommunication systems was encouraged. This communication was performed under several rules, based on the mutual respect and consideration. The task schedule published at the notice board was strictly followed. The lecturer announced topics related to the organization and logistics of the subject (change of classroom, timetable, uploading of information/document/task at the VC, etc) both via the Virtual Classroom and directly at the face-to-face class. A coherent communication system was maintained during the entire study. The logistic of the VC was successful and easy to implement, because of the permanent exchange of ideas that took place.

The use of VC allowed students:

- To retrieve knowledge, learning activities and general task scheduling.

- A live interaction with the lecturer and the classmates via e-mail, discussion forums and chat rooms.

- Receive a personalized attention from the lecturer.

- Carry out different evaluation methodologies: exams, tests with interactive questions, selfevaluation activities, presentations, projects, numerical and practical problems and tasks.

- Work online with the other students.

- Access their qualifications and have knowledge of their progression.

- Access online resources: links of interest, documents, research works, and other material related to the content of the subject.

\section{METHODOLOGY}

\subsection{Description of the Master Analytical Techniques of the Clinical Laboratory}

Clinical analysis is the scientific discipline dealing with the diagnosis, prognosis, therapeutics and prevention of diseases. For this purpose, Analytical Chemistry tools, methodology and instrumentation, are taken and adapted to their compound target and matrices. 
The Master in "Analytical Techniques of the Clinical Laboratory" (TALC) provides a multidisciplinary training in the areas of chemical, biological and biochemical sciences, as well as in health sciences such as pharmacy, medicine or nursing. This Masters offers several career opportunities to graduates in Chemistry and other scientific disciplines, like Pharmacy, Medicine, Nursing, Biology, Biochemistry, etc, and even to laboratory technicians. The students of this Master are mainly University students that have recently obtained a Scientific Degree or professionals having developed their career in the Hospital/clinical field, and wanted to increase their theoretical and-practical background in this area. Almost all the students worked and/or must attend familiar responsibilities during the class timetable. Some of them reside far from the Castelló area and cannot attend the face-to-face classes.

The Master arises from the Bioanalytical Chemistry Group of the Department of Physical and Analytical Chemistry of the UJI, after an extensive collaboration with the Reference Hospitals of Castelló: General, Provincial and La Plana on topics related to research on chemical analysis with clinical applications. The Master includes 75 ECTS credits and is taught in Valencian or Spanish, using presentations in English, during one Academic Year. It is structured in 12 compulsory subjects: Clinical Chemistry, Clinical Laboratory Instrumentation, Clinical Biochemistry, Hormones and Autoimmunity, Molecular Biopathology, Microbiology, Cytogenetics, Hematology, Oncohematology and Cellular Immunity, Clinical Laboratory Management, Biostatistics and Master Final Project (preferably related to a subject assigned to a Hospital worker). The teaching staff is made of University professors (30\%) from the Universitat Jaume I (6) and the University of Valencia (2), and Hospital facultatives (70\%) from the General de Castelló (9), La Plana de Vila-real (6) and Provincial de Castelló (4).

The didactic methodology is as follows: each subject has several theoretical and practical classes, depending on its characteristics and content. The teaching-learning activities are: theoretical training, practical training, seminaries, tutorials, evaluation, homework tasks and preparation of the exams. Face-to-face classes are taught at the University Jaume I and at the above mentioned Hospitals. Therefore, the students will be in contact with the laboratories related to the studied subjects. Besides, they will learn the assistance and research tasks developed in each center.

The Master can be studied under attendance and at distance. The students who choose this last option will receive the didactic material and will have to complete the corresponding questionnaires, assignments and exams on-line. This material will be sent directly to the student e-mail or uploaded to the Virtual Classroom. They are allowed to attend the face-to-face classes and practicals. The students, regardless their option, will be equally evaluated on the basis of the questionnaires and homework tasks.

The main objective of this Master is to provide to the student an advanced theoretical-practical training in the multidisciplinary field of health sciences, and specifically in its analytical part. This would allow them to work in both research and routine analysis positions.

\subsection{Description of the Virtual Classroom}

The VC is defined as a network internet area where teachers and students meet to develop teachinglearning activities [1]. The VC may not be considered as a simple tool to distribute the didactic material, but as a tool to host a wide range of activities related to the learning process. It should favor the interactivity, communication, knowledge transmission, student accessibility, evaluation and use in the face-to-face class. During the entire development of the project, the VC was used to complement, not to substitute, the face-to-face classes.

The lecturer speeches and the notes of the subject (as .ppt documents) were posted on the VC. Additional bibliography was also indicated, such as websites, articles and books of interest. This allowed the students to dispose of the teaching material before the class and to take notes on them, which increased their attention during the lecturer explanation. They could access them a posteriori, and therefore complete their own notes. The students that have not attended the class can get access to the content and have the content taught, even if they had not attended the class. Therefore, distance limitations were eliminated and allowed better time management. It was only necessary to have a personal computer and Internet connection, something nowadays available to practically the entire population. This was especially interesting for students who could not go to the University or the Hospital for personal or work reasons, a situation that usually occurs in this Master. Therefore, the VC facilitated distance education.

The following multimedia tools were created: 
- Public discussion forums: a forum to ask and answer issues related to the subject.

- Private tutorials: for personal conversations with the teacher. The content of the conversations were not accessible to the other students.

- Suggestion box mail: a section specially addressed to the students. Ideas were exchanged about the positive aspects and negative aspects of the subject, as well as suggestions to improve the didactic methodology. It was barely used.

- Cafeteria: a forum dedicated to discuss topics not directly related to the subject. It was not used.

- Notice board: to announce several events and news related to the subject.

- Problems: several numerical problems were posted to be solved by the students as homework tasks and further revised by the teacher.

- Self-evaluation activities: students can verify their knowledge acquisition progress before the written exam.

- Questionnaires: the students can give their opinion about the structure and the usefulness of the $\mathrm{VC}$ and several related aspects

- Comprehension test: each student was asked to propose one or two questions to check the level of proficiency of the learning content, likely to be included in the exam. The response to this activity was quite satisfactory.

The use of VC did not require special computer skills and promoted a positive attitude towards the use of the technologies of information and a higher knowledge about the use of computers. Contents of the VC were divided into several blocks, in order to the students can receive information, review resources, perform activities, self-evaluate themselves, share learning experiences and communicate among them. Therefore, the students acquired personal skills like personal commitment, organization and a mature attitude towards the educational actions.

The VC was designed as a secure environment to allow a fluid communication fluid between the student and the teacher, and among the students. The students could be in contact with their classmates and with the teacher outside the class, and even outside working hours, which partially replace the attendance tutorials. In addition, they could participate as many times as they like and were able. This is an interesting improvement respect to the traditional class, where they only have a few opportunities to ask questions during some specific preset hours per week. They were also able to share points of view with the other students and prepare group works. Each student was able to communicate with the teacher through private or open discussions, depending on the desired level of privacy. The messages sent during the tutorials were similar to the questions that are asked in the face-to-face classes, but in a higher number and about more varied topics, including outside the scope of the content of the subject. The possibility to on-line communicate with the teacher was found out as a fundamental multimedia tool to stimulate the participation and curiosity of the students. This turned the tutorials into a dynamic activity that covers learning contents beyond those of the subject, on request of the own students. This was partially due to the elimination of the physical presence of the teacher and the classmates, which usually exerts an inhibitor effect on the oral participation of the students in the classroom (the students gain confidence to asks a question as an on-line message) and the accessibility, which allows them to able to ask a doubt as soon as they come up with. Nevertheless, only a few discussion forums were opened, wherein the teachers and the students hardly participated. It should be noted that the group discussions were preferably carried out during the face-to-face classes. An intense communication among the students via the VC was not observed.

The monitoring of the use of the VC applications by the students was relevant to find out whether they consulted the documents and websites, and they regularly participated, or to sense students that are considering leaving the course.

1 It was available 24 hours a day, 365 days a year, and the proposed activities could be made at any time, depending on the student's availability

2 Only the evaluation activities had to be answered before the deadline indicated in the schedule.

3 The students organized their own learning from a point of individual view, independently of the other students of the group.

4 Encourage cooperative learning, as the students themselves were able to answer questions and questions launched by their classmates. 
5 A personal and permanent attention is provided by the teacher, and the communication among the members of the virtual community members is encouraged.

6 Feedback on the transmission of the information: teachers could perceive the degree of knowledge that the students have assimilated at any time. So, they can modify the planning of the delivery of teaching material, as well as adapting the didactic methodology and the progression in the development of the subject, in order to achieve the learning objectives initially established.

7 Use pseudonyms and / or anonymous participation: this facilitates the indication and correction of students' mistakes and to express personal opinions without bothering or embarrassing them.

Nevertheless, the use of the VC should not be considered as a definitive alternative to the traditional didactic methodologies. Some disadvantages with respect to the face-to-face classes were noticed. For instance, the students did not receive an immediate response to their queries and comments, which was frustrating for some of them. Besides, in the VC the teacher must sequentially answer to a significant number of questions (sometimes repeated), and some of them about dissimilar topics, which may be tedious. On the other hand, in a traditional class, a pleasant voice, occasional jokes, dramatic gestures and questions launched by the teacher can make a long class, more attractive for the students. Therefore, this forced the teacher to enhance his non-verbal communication skills, use a skillfully written language and to elaborate an attractive didactic material.

\subsection{Evaluation of the VC by the participants of the Master}

At the end of the academic year, we inquired about the use of the VC by the teachers and students. It was found that $40 \%$ of the teachers, all of them Hospital facultatives did not use this tool. The others (30\% university professors and $30 \%$ the other Hospital facultatives) used this tool. The $10 \%$ of the students did not use the VC, and received the teaching materials in paper, while the tasks were solved and delivered by the same way.

All the participants of the Master that used the VC were requested to fulfill a questionnaire to know their personal experience about the use, functionality and utility of the VC. Each question had a score from 1 (not agree) to 5 (agree). The results permit to verify the usefulness of this tool for teachers and students, assess the positive and negative aspects, and establish the necessary improvements. The average scores given by the teachers and the students can be seen in Tables 1 and 2, respectively.

Table 1. Satisfaction survey of the teachers on the VC.

\begin{tabular}{r|l|c}
\hline \hline$N^{\circ}$ & \multicolumn{1}{|c}{ Question } & Score \\
\hline 1 & I frequently access the VC & 3.8 \\
\hline 2 & I consider that the structure of the VC is adequate & 4.6 \\
\hline 3 & I was able to edit each section of the VC to add resources, activities and announcements & 4.8 \\
\hline 4 & I uploaded in the VC all the necessary teaching materials to take the subject & 4.4 \\
\hline 5 & I made announcements related to the logistics (change of class schedule or room) through the VC & 3.5 \\
\hline 6 & The non-attending work was announced and described in the VC & 4.5 \\
\hline 7 & I prefer that students submit the homework tasks through the VC & 2.7 \\
\hline 8 & The students asked a lot of questions & 4.5 \\
\hline 9 & The students actively participated in the debates & 3.0 \\
\hline 10 & I immediately responded to the students' questions & 3.3 \\
\hline 11 & I actively participated in the debates. & 2.6 \\
\hline 12 & The communication with the students was fluid & 4.5 \\
\hline 13 & The students actively collaborated with their classmates. & 2.5 \\
\hline 14 & I consider that the use of the VC has increased my teaching quality & 4.3 \\
\hline 15 & Overall satisfaction of the teachers with the VC & 4.5 \\
\hline \hline
\end{tabular}


Table 2. Satisfaction survey of the students on the VC.

\begin{tabular}{c|l|c}
\hline \hline$N^{\circ}$ & \multicolumn{1}{|c}{ Question } & Score \\
\hline 1 & I frequently access the VC & 4.4 \\
\hline 2 & I consider that the structure of the VC is adequate & 4.3 \\
\hline 3 & I easily find the resources, announcements and activities posted in the VC & 4.7 \\
\hline 4 & The didactic material uploaded to the VC was sufficient to take the course & 4.6 \\
\hline 5 & I heard about the logistics of the course (timetable and classroom) thanks to the VC & 3.8 \\
\hline 6 & I accessed to the information regarding the homework tasks through the VC & 4.6 \\
\hline 7 & I delivered the homework problems, tasks and questionnaires through the VC & 4.5 \\
\hline 8 & I asked many doubts & 4.5 \\
\hline 9 & I actively participated in the debates & 2.4 \\
\hline 10 & The teacher quickly answered to my queries & 3.0 \\
\hline 11 & The teacher actively participated in the debates I participated & 2.8 \\
\hline 12 & The communication with the teacher was fluid & 4.8 \\
\hline 13 & I helped other students through the VC & 2.2 \\
\hline 14 & I was helped by other students via the VC & 2.0 \\
\hline 15 & The VC was useful to assimilate the contents of the subject & 4.4 \\
\hline 16 & Overall satisfaction of the students with the AV & 4.4 \\
\hline \hline
\end{tabular}

In general, teachers and positively appreciate their experience in the VC and thought that it was a useful tool to improve teaching. Both groups positively evaluated similar aspects: mutual submission of documents (didactic material and activities) and information without any time or space limitations, as well as the possibility to instantly ask questions and facilitate teacher-student communication. They consider the teachers had to respond more quickly to the questions of the students. They did not consider that the VC was useful for team communication or to stimulate the cooperative learning, perhaps because they thought that these activities are more effective if performed face-to-face. The teachers preferred to receive the homework tasks in paper, unlike the students, which preferred the electronic way. This was the major discrepancy between the two groups. On the other hand, the students frequently accessed the VC and mainly consider that it was correctly structured, and it was easy to find the different sections. The supplied didactic material was sufficient to take the classes.

\section{CONCLUSIONS}

The use of the modern information and communication technologies allows to apply the same didactic methodology to face-to-face and distance students of the classes, as if they were in the same class. It is probably their major advantage. To take full advantage of the potentialities of the VC, students only need a computer and internet connection, sufficient written and oral communication skills as well as time, motivation and discipline to regularly participate. Both teachers and students believe that the VC is a useful tool for teaching, especially because it facilitates the submission of documents and teaching materials, as well as the communication between them.

The results of the studies carried out are inconclusive about what it is better: the traditional class or that uses the Virtual Classroom. This depends on the situation. In general, the VC is useful for motivated and prepared students, who have access to the necessary equipment and who know how to take advantage of this tool to increase their interaction with the teacher and the other students, and who actively participate in the course. The teacher has a major role in the success of the VC. The methodology using VC would be "better" that the traditional one if the teacher correctly uses the VC, is able to build or maintain a collaborative and cooperative learning group, through the introduction material and information useful, didactic and that stimulate communication among the students. 


\section{ACKNOWLEDGMENTS}

The article has been written with the support of the Unitat de Suport Educatiu of the University Jaume I, by projects GIE-Química Bioanalítica, GIE-Innovació Educativa 3431/17 and GIE-Mobilitat 3537/18.

\section{REFERENCES}

[1] W. Horton. "Designing web based training", Wiley Computer Publisher, New York, USA, 2000. 